\title{
The Connection between Serum Level of Paraoxonase (PON 1) and Atherogenesis in Egyptian Patients with Type II Diabetes Mellitus

\author{
Department of Medical Biochemistry, Faculty of Medicine, Al-Azhar University, Assiut, Egypt \\ *Corresponding author: Ahmed Essa Fahmy, Mobile: (+20) 01013767213, E-Mail: ahmedessaaldiry@ gmail.com
} \\ EL-Saeed Mostafa El-Saeed Elbawab, Sameh Salah-El-din El-Saed Mohamed, Ahmed Essa Fahmy*
}

\begin{abstract}
Background: Diabetes is considered a health problem all around the world that affects people at different age levels with increasing incidence and spread of disease leading to many complications. Paraoxonase is known as an antioxidant enzyme, it was originally found to stimulate the hydrolysis of paraoxonase and has a wide range of important analytical activities.

Objective: To evaluate the serum level of paraoxonase1 (PON 1) in patients with type 2 diabetes mellitus with or without hypertension as a predictor marker of atherogenesis.

Patients and methods: This study was a case-control study and carried out on 90 persons ( 45 males, 45 females) they were selected from the outpatient and inpatient clinic of Qena University Hospital. The study was conducted during the period between October 2019 and March 2020.

Results: There was an increase in the level of blood glucose, serum cholesterol, serum triglycerides, serum LDL, serum Hs CRP, decreased serum PON 1, and serum HDL in (diabetic group) as compared to (healthy individuals group). The study also showed a positive correlation between the decreased level of serum PON 1 in patients and decreased serum HDL. The study also showed a negative correlation between the decreased level of serum PON 1 and increased serum glucose serum cholesterol, serum triglycerides, serum LDL, and serum Hs CRP. Also, measurement of serum PON 1 may become a useful, expanding tool for evaluating atherogenesis diabetes and hypertension. Conclusion: Therefore, measurement of the proportion of serum PON 1 as a biomarker of atherogenesis in Egyptian patients with type 2 diabetes mellitus.
\end{abstract}

Keywords: Paraoxonase (PON 1), Atherogenesis, Type II Diabetes Mellitus.

\section{INTRODUCTION}

Diabetes mellitus is a group of metabolic diseases characterized by chronic hyperglycemia resulting from defects in insulin secretion, insulin action, and or both. The chronic hyperglycemia of diabetes is associated with long-term damage, failure of different organs, especially the eyes, kidneys, nerves, heart, and blood vessels. The basis of the abnormalities in carbohydrate, fat, and protein metabolism in diabetes is the deficient action of insulin on target tissues ${ }^{(\mathbf{1})}$.

Diabetes mellitus (DM) and essential hypertension are common conditions that are frequently present together. Both are considered risk factors for cardiovascular disease, microvascular complications, and therefore treatment of both conditions is essential (2). It is well known that there is an increased prevalence of hypertension among patients with type II DM, and hypertension is often present at the time of diagnosis ${ }^{(3)}$.

Diabetes mellitus is classified into two types:

(1) Insulin-dependent diabetes mellitus: Type 1 diabetes mellitus (T1DM) is characterized by an absolute deficiency of insulin, is seen most often in children and adolescents.

(2) Non-insulin-dependent diabetes mellitus: Type 2 diabetes mellitus (T2DM) is caused by insulin resistance, inadequate secretion of insulin, is generally associated with overweight and obesity ${ }^{(4)}$.
Progression from pre-diabetes to type $2 \mathrm{DM}$ can be prevented or delayed in some patients through lifestyle interventions and/or metformin ${ }^{(5)}$.

Paraoxonase 1 (PON 1) is a protein of 354 amino acids with a molecular mass of $43 \mathrm{kDa}$. The amino acid arginine at position 192 of the protein specifies high activity whereas glutamine at that position specifies low-activity against paraoxon, the former has been also termed band the latter $\mathrm{A}$ (the currently recommended nomenclature is $\mathrm{R}$ and $\mathrm{Q}$ respectively). The $\mathrm{B}$ enzyme is stimulated by one mol L-1 $\mathrm{NaCl}$ to a greater extent than the A enzyme ${ }^{(6)}$.

Human paraoxonase (PON) is a $\mathrm{Ca}^{++}$-dependent esterase synthesized in the liver. PON is related to highdensity lipoprotein (HDL) ${ }^{(7)}$. PON 1 has two main roles: detoxifying organophosphate compounds such as paraoxon and protecting low-density lipoprotein (LDL) by hydrolysis of lipid peroxides ${ }^{\left({ }^{8}\right)}$. This study aimed to evaluate the serum level of paraoxonase 1 (PON 1) in patients with type 2 diabetes mellitus with or without hypertension as a predictor marker of atherogenesis. Lower paraoxonase 1 (PON 1) levels had been recognized as a risk factor for atherogenesis in patients with diabetes mellitus and hypertension.

The connection between the serum level of paraoxonase 1 (PON 1) and atherogenesis in Egyptian patients with type II diabetes mellitus. 


\section{SUBJECTS AND METHODS}

This study was a case-control study and carried out on 90 persons (45 males, 45 females) they were selected from the Outpatient and Inpatient Clinic of Qena University Hospital, divided into three groups:

The first group (Control group): composed of 30 healthy people (15 males and 15 females) with no history of diseases such as hypertension, diabetes, inflammation, tumors, and cardiovascular disease.

The second group (Diabetic group): normotensive patients with type II DM and composed of 30 patients (15 males and 15 females).

The third group (Diabetic and hypertensive group): hypertensive patients (diastolic blood pressure 90 $\mathrm{mmHg}$ or more) with type II DM and composed of 30 patients ( 15 males and 15 females).

The study was conducted during the period between October 2019 and March 2020.

\section{Ethical considerations:}

The study was approved by the Ethics Board of Al-Azhar University.Informed written consent was obtained from all participants. The type II DM diagnosis was assessed by a specialist in the Internal Medicine Department at Al-Azhar Assiut Hospital and was selected by determining their fasting and 2 hours postprandial blood glucose.

\section{Inclusion Criteria:}

- This study was designated for patients of an age > 30 years (range: $31-40$ ).

- $\quad$ Normotensive Type II Diabetic patients.

- Hypertensive Type II Diabetic patients.

- Treatment was stopped at the time of the study.

- Supine diastolic and systolic blood pressures were measured three times, with one min intervals, using a standard sphygmomanometer after resting for 10 minutes.

$\bullet$

\section{Exclusion Criteria:}

- Patients younger than 30 years old and older than 40 years old.

- Unstable, severe, or secondary hypertension.

- Atrioventricular block exceeding the first degree and not permanently paced.

- Angina pectoris

- Severe heart failure

- Hepatic failure
- Renal insufficiency

- Hypertensive patients were being treated with antihypertensive drugs.

All participants in this study were subjected to full history, complete clinical examination, and electrocardiogram.

\section{Blood samples:}

- Peripheral venous blood samples were taken from all patients after overnight fasting to analyze

- Lipid profiles (total cholesterol, triglycerides, HDL cholesterol, and LDL cholesterol).

- Glucose levels fasting and 2 hours postprandial.

- Serum level of PON 1

- Serum level of hs CRP

- Serum PON 1 was measured by enzyme-linked immune sorbent assay (ELISA). Fasting, postprandial blood glucose, cholesterol, triglycerides, LDL, HDL, were measured by Microlab semi-automated chemistry analyzer. Hs CRP was measured by enzyme-linked immune sorbent assay (ELISA).

\section{Statistical analysis}

Recorded data were analyzed using the statistical package for social sciences, version 20.0 (SPSS Inc., Chicago, Illinois, USA). Quantitative data were expressed as mean \pm standard deviation (SD). Qualitative data were expressed as frequency and percentage. Independentsamples t-test of significance was used when comparing two means. The confidence interval was set to $95 \%$ and the margin of error accepted was set to $5 \%$. The p-value was considered significant as the following: P-value $<0.05$ was considered significant. P-value $<0.001$ was considered as highly significant. P-value $>0.05$ was considered insignificant.

\section{RESULTS}

The value of female was the same as the value of male in controls and cases. There was no statistically significant difference between controls, cases regarding age. The mean value of LDL, TG, cholesterol, FBG, PPBG and Hs CRP was statistically significant higher $(\mathrm{p} \leq 0.0)$ among cases than controls. The mean value of HDL was statistically significant lower among cases than controls and $\mathrm{P}$ value was 0.001 .

The mean value of paraoxonase $1(\mathrm{U} / \mathrm{L})$ was statistically significant lower among cases than controls and $\mathrm{P}$ value was 0.008 (Table 1). 
Table (1): Comparison between controls and cases regarding sex, age, LDL, HDL, TG, cholesterol, Hs CRP, paraoxonase 1, FBG, and PPBG.

\begin{tabular}{|c|c|c|c|c|c|c|}
\hline & & & Controls & Cases & P-value & Sig. \\
\hline \multirow[t]{4}{*}{ Sex } & \multirow[t]{2}{*}{ Female } & No. & 15 & 30 & \multirow[t]{4}{*}{1.000} & \multirow[t]{4}{*}{ N.S } \\
\hline & & $\%$ & $50.0 \%$ & $50.0 \%$ & & \\
\hline & \multirow[t]{2}{*}{ Male } & No. & 15 & 30 & & \\
\hline & & $\%$ & $50.0 \%$ & $50.0 \%$ & & \\
\hline Age (years) & \multicolumn{2}{|c|}{ Mean \pm SD } & $35.73 \pm 3.61$ & $34.82 \pm 3.54$ & 0.253 & N.S \\
\hline LDL (mg/dL) & \multicolumn{2}{|c|}{ Mean \pm SD } & $88.80 \pm 8.83$ & $142.84 \pm 35.27$ & 0.001 & H.S \\
\hline HDL (mg/dL) & \multicolumn{2}{|c|}{ Mean \pm SD } & $50.30 \pm 3.22$ & $41.45 \pm 4.15$ & 0.001 & H.S \\
\hline TG (mg/dL) & \multicolumn{2}{|c|}{ Mean \pm SD } & $132.50 \pm 11.81$ & $236.78 \pm 50.79$ & 0.001 & H.S \\
\hline Chol. (mg/dL) & \multicolumn{2}{|c|}{ Mean \pm SD } & $165.57 \pm 9.96$ & $231.65 \pm 34.49$ & 0.001 & H.S \\
\hline Hs CRP $(\mathrm{mg} / \mathrm{dL})$ & \multicolumn{2}{|c|}{ Mean \pm SD } & $0.793 \pm 0.119$ & $11.59 \pm 3.949$ & 0.001 & H.S \\
\hline Paraoxonase 1 (U/L) & \multicolumn{2}{|c|}{ Mean \pm SD } & $44.02 \pm 10.79$ & $34.29 \pm 16.68$ & 0.001 & H.S \\
\hline FBG $(\mathrm{mg} / \mathrm{dL})$ & \multicolumn{2}{|c|}{ Mean \pm SD } & $85.93 \pm 8.61$ & $185.32 \pm 44.28$ & 0.001 & H.S \\
\hline PPBG (mg/dL) & \multicolumn{2}{|c|}{ Mean \pm SD } & $113.87 \pm 7.257$ & $326.67 \pm 82.08$ & 0.001 & H.S \\
\hline
\end{tabular}

There was no statistically significant difference between controls, diabetic, diabetic and hypertension cases regarding sex. This table showed that the mean of age in controls, diabetic , diabetic, hypertension cases. There was no statistically significant difference between controls, cases regarding age. The mean value of LDL was statistically highly significant in diabetic and diabetic with hypertemsion than control. The mean value of HDL was statistically significant low among diabetic and diabeticwith hypertension cases in comparison with control (Table 2).

The mean values of TG, cholesterol , Hs CRP, PPBG and FBG were statistically significant high among diabetic and diabetic, hypertension cases as compared to control. The mean value of paraoxonase 1 was statistically significant low among diabetic, hypertension cases .

Table (2): Comparison between (controls), (diabetic cases), (diabetic and hypertension cases) regarding sex, age, LDL TG, cholesterol, HsCRP, Paraoxonase 1, FBG, and PPBG.

\begin{tabular}{|c|c|c|c|c|c|c|c|}
\hline & & & Controls & piabetic cases & $\begin{array}{c}\text { Diabetic and } \\
\text { hypertension cases }\end{array}$ & P-value & Sig. \\
\hline \multirow[t]{4}{*}{ Sex } & \multirow[t]{2}{*}{ Female } & No. & 15 & 15 & 15 & \multirow[t]{4}{*}{1.00} & \multirow[t]{4}{*}{ N.S } \\
\hline & & $\%$ & $50.0 \%$ & $50.0 \%$ & $50.0 \%$ & & \\
\hline & \multirow[t]{2}{*}{ Male } & No. & 15 & 15 & 15 & & \\
\hline & & $\%$ & $50.0 \%$ & $50.0 \%$ & $50.0 \%$ & & \\
\hline Age (years) & \multicolumn{2}{|c|}{ Mean \pm SD } & $35.73 \pm 3.61$ & $34.73 \pm 3.65$ & $34.90 \pm 3.48$ & 0.514 & N.S \\
\hline $\begin{array}{c}\text { LDL } \\
(\mathbf{m g} / \mathbf{d L})\end{array}$ & \multicolumn{2}{|c|}{ Mean \pm SD } & $88.80 \pm 8.83$ & $143.44 \pm 34.25$ & $142.25 \pm 33.84$ & $\begin{array}{l}\mathrm{P} 1=0.001 \\
\mathrm{P} 2=0.001 \\
\mathrm{P} 3=0.876\end{array}$ & $\begin{array}{l}\text { H.S } \\
\text { H.S } \\
\text { N.S }\end{array}$ \\
\hline $\begin{array}{c}\text { HDL } \\
(\mathrm{mg} / \mathrm{dL})\end{array}$ & \multicolumn{2}{|c|}{ Mean \pm SD } & $50.30 \pm 3.22$ & $40.27 \pm 4.26$ & $42.63 \pm 3.75$ & $\begin{array}{l}\mathrm{P} 1=0.001 \\
\mathrm{P} 2=0.001 \\
\mathrm{P} 3=0.017\end{array}$ & $\begin{array}{l}\text { H.S } \\
\text { H.S } \\
\text { S }\end{array}$ \\
\hline $\begin{array}{c}\text { TG } \\
(\mathbf{m g} / \mathbf{d L})\end{array}$ & \multicolumn{2}{|c|}{ Mean \pm SD } & $132.50 \pm 11.81$ & $29.97 \pm 56.43$ & $243.60 \pm 44.37$ & $\begin{array}{l}\mathrm{P} 1=0.001 \\
\mathrm{P} 2=0.001 \\
\mathrm{P} 3=0.212\end{array}$ & $\begin{array}{l}\text { H.S } \\
\text { H.S } \\
\text { N.S }\end{array}$ \\
\hline $\begin{array}{c}\text { Cholesterol } \\
(\mathrm{mg} / \mathrm{dL})\end{array}$ & \multicolumn{2}{|c|}{ Mean \pm SD } & $165.57 \pm 9.96$ & $29.70 \pm 34.61$ & $233.60 \pm 34.86$ & $\begin{array}{l}\mathrm{P} 1=0.001 \\
\mathrm{P} 2=0.001 \\
\mathrm{P} 3=0.603\end{array}$ & $\begin{array}{l}\text { H.S } \\
\text { H.S } \\
\text { N.S }\end{array}$ \\
\hline $\begin{array}{r}\text { HsCRP } \\
(\mathrm{mg} / \mathrm{L})\end{array}$ & \multicolumn{2}{|c|}{ Mean \pm SD } & $0.79 \pm 0.12$ & $8.56 \pm 2.81$ & $14.62 \pm 2.19$ & $\begin{array}{l}\mathrm{P} 1=0.001 \\
\mathrm{P} 2=0.001 \\
\mathrm{P} 3=0.001\end{array}$ & $\begin{array}{l}\text { H.S } \\
\text { H.S } \\
\text { H.S }\end{array}$ \\
\hline $\begin{array}{l}\operatorname{araoxonase} 1 \\
(\mathrm{U} / \mathrm{L})\end{array}$ & \multicolumn{2}{|c|}{ Mean \pm SD } & $44.02 \pm 11.79$ & $36.63 \pm 1.48$ & $31.96 \pm 2.19$ & $\begin{array}{l}\mathrm{P} 1=0.076 \\
\mathrm{P} 2=0.004 \\
\mathrm{P} 3=0.260\end{array}$ & $\begin{array}{c}\text { N.S } \\
\text { S } \\
\text { N.S } \\
\end{array}$ \\
\hline $\begin{array}{c}\text { FBG } \\
(\mathrm{mg} / \mathrm{dL})\end{array}$ & \multicolumn{2}{|c|}{ Mean \pm SD } & $85.93 \pm 8.61$ & $204.17 \pm 50.20$ & $166.47 \pm 38.88$ & $\begin{array}{l}\mathrm{P} 1=0.001 \\
\mathrm{P} 2=0.001 \\
\mathrm{P} 3=0.001\end{array}$ & $\begin{array}{l}\text { H.S } \\
\text { H.S } \\
\text { H.S }\end{array}$ \\
\hline PPBG & \multicolumn{2}{|c|}{ Mean \pm SD } & $113.87 \pm 7.26$ & $352.67 \pm 8.59$ & $300.67 \pm 73.59$ & $\begin{array}{l}\mathrm{P} 1=0.001 \\
\mathrm{P} 2=0.001 \\
\mathrm{P} 3=0.005\end{array}$ & $\begin{array}{l}\text { H.S } \\
\text { H.S } \\
\text { H.S }\end{array}$ \\
\hline
\end{tabular}

P1-- $\rightarrow$ (Controls) and (Diabetic cases), P2-- $\rightarrow$ (Controls) and (Diabetic and hypertension cases), P3-- $\rightarrow$ (Diabetic cases) and (Diabetic and hypertension cases) 
This table showed that the correlation between paraoxonase 1 and other numerical data. There were statistically significant negative correlations between Paraoxonase 1 and (LDL, Cholesterol, Hs CRP, FBG, PPBG). There were statistically significant postive correlations between paraoxonase 1 and HDL (Table 3 ).

Table (3): Correlation between paraoxonase 1 (U/L) and other numerical data.

\begin{tabular}{|l|c|c|}
\hline \multicolumn{1}{|c|}{ Correlation } & \multicolumn{2}{c|}{ Pearson's correlation } \\
\cline { 2 - 3 } & $\mathbf{r}$ & $\mathbf{p}$ \\
\hline \hline LDL $(\mathrm{mg} / \mathrm{dL}) *$ Paraoxonase 1 (U/L) & $-0.272-$ & 0.010 \\
\hline HDL (mg/dL) * Paraoxonase 1 (U/L) & 0.186 & 0.080 \\
\hline TG (mg/dL) * Paraoxonase 1 (U/L) & $-0.150-$ & 0.158 \\
\hline Cholesterol (mg/dL) * Paraoxonase 1 (U/L) & $-0.269-$ & 0.010 \\
\hline Hs CRP (mg/L) * Paraoxonase 1 (U/L) & $-0.240-$ & 0.023 \\
\hline FBG (mg/dL) * Paraoxonase 1 (U/L) & $-0.232-$ & 0.028 \\
\hline PPBG (mg/dL) * Paraoxonase 1 (U/L) & $-0.266-$ & 0.011 \\
\hline
\end{tabular}

\section{DISCUSSION}

Diabetes mellitus, hypertension are both associated with increased oxidative stress and changes in antioxidant enzyme activities. The increased oxidative stress in type 2 DM may result from changes in energy metabolism, alterations in sorbitol pathway activity, changes in the level of inflammatory mediators, the status of the antioxidant defense systems, or localized tissue damage following hypoxia and ischemic reperfusion injury ${ }^{(9)}$.

Maxwell et al. ${ }^{(10)}$ also suggest that persistent hyperglycemia promotes nonenzymatic glycosylation of proteins and local free radical production.

In this study,serum paraoxonase 1 level was decreased in patients with (diabetic group), (diabetic, hypertension group) as compared with the (controls group) suggesting that serum paraoxonase 1 as a marker of diabetes and hypertension.

These results were in agreement $\mathrm{P}$-value with Mackness et al. ${ }^{(11)}$ who showed a reduction in PON 1 in patients with insulin-dependent diabetes mellitus (IDDM). Serum paraoxonase was significantly lower in IDDM populations than in controls $67 \%$ of the IDDM population was in the lower half of the frequency distribution for serum paraoxonase 1 .

Ebtehaj et al. ${ }^{(12)}$ stated that decreased antiinflammatory protection capacity of HDL conceivably contributes to the increased atherosclerosis risk associated with T2DM. The HDL anti-inflammatory capacity is substantially impaired in T2DM at least partly attributable to the degree of hyperglycemia and decreased PON-1.

Connelly et al. ${ }^{(13)}$ stated that lower mass of PON 1; an anti-inflammatory HDL-associated enzyme in T2DM may contribute to their increased risk for cardiovascular disease. An interaction between the inflammatory and metabolic changes in diabetes results in lower serum PON 1. The extent to which the lower PON 1, subsequent reduction in the anti-inflammatory function of HDL contributes to vascular and renal changes remains to be determined.

Dullaart et al. ${ }^{(14)}$ stated that PON-1, HDL cholesterol, and apoA-I were decreased in T2DM $(p<0.05)$. The inverse relationship of PON-1 with T2DM was only modestly attenuated by HDL cholesterol or HDL particle characteristics. Impaired PON-1 in T2DM is not a considerable extent explained by altered HDL subfraction levels.

In contrary to our results Sözmen et al. (15) showed no difference in PON 1 in controls or either patient group. These data suggest that antioxidant enzyme activities are affected more by the severity of diabetes than the duration of the disease. These data suggest that antioxidant enzyme activities are affected more by the severity of diabetes. There was no change in PON 1 regarding the duration of diabetes and patients who had hypertension for more than either 5 or 10 years; had reduced basal/salt-stimulated PON 1 compared with patients with less than 5 or 10 years of hypertension history.

Kunutsor et al. ${ }^{(16)}$ stated that serum HDL-C concentration was inversely and independently associated with the risk of type 2 diabetes.

In the present study serum Hs CRP levels were increased in patients with (diabetic group), (diabetic, hypertension group) as compared with the (control group) suggesting that serum Hs CRP as a marker of diabetes, hypertension. This result was in agreement with Ebtehaj et al. ${ }^{(12)}$

Stępień et al. ${ }^{(17)}$ stated that serum Hs CRP levels $(\mathrm{mg} / \mathrm{L})$ in (low cardiovascular risk), (moderate cardiovascular risk), (high cardiovascular risk) were $0.83 \pm 0.26,1.8 \pm 0.6$, and $4.9 \pm 1.7$ respectively.

In the present study serum cholesterol levels were increased in diabetic group, diabetic, hypertension group as compared with the control group .These results were in agreement with Sözmen et al. ${ }^{(15)}$ and Mahfouz et al. ${ }^{(18)}$.These results were in disagreement with Umapathy et al. ${ }^{(19)}$. 
Serum triglyceride levels were increased in patients with (diabetic group), (diabetic, hypertension group) as compared with the (control group) .These results were in agreement with Sözmen et al. ${ }^{(15)}$ and Umapathy et al. ${ }^{(19)}$. This result was in disagreement with Han et al. ${ }^{(20)}$.

In the present study serum LDL-cholesterol levels were increased in diabetic group, diabetic with hypertension group as compared with the (control group) .This result was in agreement with Mahfouz et al. ${ }^{(18)}$ .Also, this result was in agreement with Umapathy et al. (19) . Our results were in disagreement with Sözmen et al. (15) . In the present results serum HDL-cholesterol levels were decreased in diabetic group, diabetic, with hypertension group as compared with controls group .These results were in agreement with Ebtehaj et al. ${ }^{(12)}$ and Umapathy et al. (19) .These results were in disagreement with Han et al. ${ }^{(20)}$.

In the present study serum fasting blood glucose levels were increased in diabetic group, diabetic with hypertension group as compared with control group. These results were in agreement with Sözmen $\boldsymbol{e t}$ al. ${ }^{(15)}$ and Elsayed et al. ${ }^{(21)}$.

In the present study serum postprandial blood glucose levels were increased in diabetic group, diabetic with hypertension group as compared with the control group. These results were in agreement with Elsayed $\boldsymbol{e t}$ al. ${ }^{(21)}$. In the present study paraoxonase 1 had a negative correlation with dyslipidemia. Ebtehaj et al. ${ }^{(12)}$ stated that T2DM was associated with lower PON-1 activity, impaired HDL anti-inflammatory capacity, coinciding with decreased HDL cholesterol and apolipoprotein A-I. PON-1 showed a positive association with HDL-C, inverse relation with lipid peroxides, and no association with antioxidant vitamins in healthy subjects ${ }^{(22)}$. In the present study paraoxonase 1 had a negative correlation with blood sugar. Ebtehaj et al. (12) stated that T2DM was associated with hyperglycemia and lower PON-1 activity . In the present study paraoxonase 1 had a negative correlation with $\mathrm{Hs}$ CRP. This result was in agreement with Ebtehaj et al. (12) who stated that T2DM was associated with lower PON-1 activity and higher hs-CRP .

\section{CONCLUSION}

Therefore, the measurement of the proportion of serum PON 1 is considered as a biomarker of atherogenesis in Egyptian patients with type 2 diabetes mellitus.

\section{RECOMMENDATIONS}

Serum paraoxonase 1 promises to open up new strategies based on these findings for the diagnosis, follow up treatment of numerous pathological status associated with diabetes and hypertension. Serum paraoxonase 1 level is useful as a biomarker in diabetes.

We hope for more advanced research on a large number including male, female Egyptian with diabetes mellitus and hypertension.
1. American Diabetes Association (2019): Classification and diagnosis of diabetes: standards of medical care in diabetes2019. Diabetes Care, 42(1): 13-28.

2. Grossman A, Grossman E (2017): Blood pressure control in type 2 diabetic patients. Cardiovasc Diabetol., 16(1): 3-5.

3. Cohn J (2001): Arterial Compliance to Stratify Cardiovascular Risk: More Precision in Therapeutic Decision Making. Am J Hypertens., 14:258-263.

4. Marathe P, Gao H, Close $K$ (2017): American Diabetes Association Standards of Medical Care in Diabetes. J Diabetes, 9: 320-4.

5. Hogue A, Huntington $M$ (2017): Prevention, Detection, and Management of Diabetes in South Dakota SD Med. Spec., 4: 4753.

6. Josse D (2002): Paraoxonase 1 structure. In Paraoxonase (PON1) in health and disease basic and clinical aspects edited by Costa $\mathrm{L}$. and Furlong C. Published by Kluwer Academic Publishers, 53:4045.

7. Harel M, Aharoni A, Gaidukov L et al. (2004): Structure and evolution of the serum paraoxonase family of detoxifying and antiatherosclerotic enzymes. Nat Struct Mol Biol., 11: 412-419.

8. Billecke S, Draganov D, Counsell R et al. (2000): Human serum paraoxonase (PON 1) isozymes $\mathrm{Q}$ and $\mathrm{R}$ hydrolyze lactones and cyclic carbonate esters. Drug Metab Dispos., 28: 1335-1342.

9. Baynes J (1991): Role of oxidative stress in the development of complications in diabetes. Diabetes, 40: 405-12.

10. Maxwell S, Thomason H, Sandler D et al. (1997): Poor glycaemic control is associated with reduced serum free radical scavenging (antioxidant) activity in non-insulin-dependent diabetes mellitus. Ann Clin Biochem., 34: 638-44.

11. Mackness M, Harty D, Bhatnagar D et al. (1991): Serum paraoxonase activity in familial hypercholesterolemia and insulindependent diabetes mellitus. Atherosclerosis, 86: 193-9.

12. Ebtehaj S, Gruppen E, Parvizi M et al. (2017): The antiinflammatory function of HDL is impaired in type 2 diabetes: role of hyperglycemia, paraoxonase-1, and low-grade inflammation. Cardiovasc Diabetol., 16(1):132-35.

13. Connelly P, Zinman B, Maguire G et al. (2009): Association of the novel cardiovascular risk factors paraoxonase 1 and cystatin $\mathrm{C}$ in type 2 diabetes. Journal of Lipid Research, 50(6): 1216-1222.

14. Dullaart R, Otvos J, James R. (2014): Serum paraoxonase-1 activity is more closely related to HDL particle concentration and large HDL particles than to HDL cholesterol in Type 2 diabetic and non-diabetic subjects. Clinical Biochemistry, 47(12): 10221027.

15. Sözmen B, Delen F, Girgin E et al. (1999): Catalase and Paraoxonase in Hypertensive Type 2 Diabetes Mellitus: Correlation With Glycemic Control. Clin Biochem., 32 (6): 4237.

16. Kunutsor S, Kieneker L, Bakker S et al. (2017): Incident type 2 diabetes is associated with HDL, but not with its anti-oxidant constituent-paraoxonase-1: the prospective cohort PREVEND study. Metabolism, 73: 43-51.

17. Stępień M, Stępień A, Wlazeł $R$ et al. (2014): Obesity indices and inflammatory markers in obese non-diabetic normo-and hypertensive patients: a comparative pilot study. Lipids in Health and Disease, 13(1): 29-33.

18. Mahfouz M, Assiri A, Mukhtar M (2016): Assessment of Neutrophil Gelatinase-Associated Lipocalin (NGAL) and RetinolBinding Protein 4 (RBP4) in Type 2 Diabetic Patients with Nephropathy. Biomark Insights, 11: 31-40.

19. Umapathy D, Dornadula S, Krishnamoorthy E et al. (2018): YKL-40: A biomarker for early nephropathy in type 2 diabetic patients and its association with inflammatory cytokines. Immunobiology, 223(11): 718-727.

20. Han J, Ma X, Yu, L et al. (2015): Correlation between serum YKL-40 levels and albuminuria in type 2 diabetes. Genet Mol Res., 14(4): 18596-603.

21. Elsayed M, El Badawy A, Omar R et al. (2019): Serum cystatin $\mathrm{C}$ as an indicator for early detection of diabetic nephropathy in type 2 diabetes mellitus. Diabetes \& Metabolic Syndrome: Clinical Research \& Reviews, 13(1): 374-381. 
22. Jayakumari N, Thejaseebai G. (2009): High Prevalence of Low Serum Paraoxonase-1 in Subjects with Coronary Artery Disease. Journal of Clinical Biochemist, 45: 3-7. 